\title{
Pirfenidone modulates macrophage polarization and ameliorates radiation-induced lung fibrosis by inhibiting the TGF-ק1/Smad3 pathway
}

\author{
Hangjie Ying ${ }^{1,2}$ @ | Min Fang ${ }^{1,2,3}$ | Qing Qing Hang ${ }^{4}$ | Yamei Chen ${ }^{1,2}$ | Xu Qian ${ }^{1,5}$ | \\ Ming Chen ${ }^{1,2,3}$
}

\author{
${ }^{1}$ Institute of Basic Medicine and Cancer \\ (IBMC), The Cancer Hospital of the \\ University of Chinese Academy of \\ Sciences (Zhejiang Cancer Hospital, \\ Chinese Academy of Sciences, Hangzhou, \\ China \\ ${ }^{2}$ Zhejiang Key Laboratory of Radiation \\ Oncology, Zhejiang Cancer Hospital, \\ Hangzhou, China \\ ${ }^{3}$ The Department of Thoracic \\ Radiotherapy, Zhejiang Cancer Hospital, \\ Hangzhou, China \\ ${ }^{4}$ The Second Clinical Medical College of \\ Zhejiang, Chinese Medical University, \\ Hangzhou, China \\ ${ }^{5}$ The Department of Clinical Laboratory, \\ Zhejiang Cancer Hospital, Hangzhou, \\ China
}

\section{Correspondence}

Ming Chen, Institute of Basic Medicine and Cancer (IBMC), The Cancer Hospital of the University of Chinese Academy of Sciences (Zhejiang Cancer Hospital), Chinese Academy of Sciences, No.1 East Banshan Road, Gongshu District, Hangzhou, Zhejiang, China 310022. Email: chenming@zjcc.org.cn

Funding information National Natural Science Foundation of China, Grant/Award Number: 81703018; Natural Science Foundation of Zhejiang Province, Grant/Award Number: LY21H160004; Medical Health Science and Technology Project of Zhejiang Provincial Health Commission, Grant/Award Number: 2020KY466 and 2021KY084

\begin{abstract}
Radiation-induced lung injury (RILI) mainly contributes to the complications of thoracic radiotherapy. RILI can be divided into radiation pneumonia (RP) and radiation-induced lung fibrosis (RILF). Once RILF occurs, patients will eventually develop irreversible respiratory failure; thus, a new treatment strategy to prevent RILI is urgently needed. This study explored the therapeutic effect of pirfenidone (PFD), a Food and Drug Administration (FDA)-approved drug for (IPF) treatment, and its mechanism in the treatment of RILF. In vivo, C57BL/6 mice received a 50 Gy dose of X-ray radiation to the whole thorax with or without the administration of PFD. Collagen deposition and fibrosis in the lung were reversed by PFD treatment, which was associated with reduced M2 macrophage infiltration and inhibition of the transforming growth factor- $\beta 1$ (TGF- $\beta 1$ )/Drosophila mothers against the decapentaplegic 3 (Smad3) signalling pathway. Moreover, PFD treatment decreased the radiation-induced expression of TGF- $\beta 1$ and phosphorylation of Smad3 in alveolar epithelial cells (AECs) and vascular endothelial cells (VECs). Furthermore, IL-4-induced M2 macrophage polarization and IL-13-induced M2 macrophage polarization were suppressed by PFD treatment in vitro, resulting in reductions in the release of arginase-1 (ARG-1), chitinase 3-like 3 (YM-1) and TGF- $\beta 1$. Notably, the PFD-induced inhibitory effects on M2 macrophage polarization were associated with downregulation of nuclear factor kappa-B (NF-кB) p50 activity. Additionally, PFD could significantly inhibit ionizing radiation-induced chemokine secretion in MLE-12 cells and consequently impair the migration of RAW264.7 cells. PFD could also eliminate TGF- $\beta 1$ from M2 macrophages by attenuating the activation of TGF- $\beta 1 / \mathrm{Smad} 3$. In conclusion, PFD is a potential therapeutic agent to ameliorate fibrosis in RILF by reducing M2 macrophage infiltration and inhibiting the activation of TGF- $\beta 1 /$ Smad3.
\end{abstract}


KEYWORDS

ionizing radiation, macrophages, pirfenidone, radiation-induced lung fibrosis, transforming growth factor- $\beta 1$

\section{1 | INTRODUCTION}

Radiotherapy is a standardized treatment for thoracic tumours such as lung cancer, ${ }^{1}$ oesophageal cancer, ${ }^{2}$ malignant lymphoma ${ }^{3}$ and breast cancer. ${ }^{4}$ Clinical data show that the incidence of radiation-induced lung injury (RILI) is 5\%-25\% after radiation therapy in patients with lung cancer, followed by those with mediastinal lymphoma (5\%-10\%) and breast cancer (1\%-5\%). ${ }^{5}$ There are two clinical manifestations of RILI: radiation pulmonary (RP) and radiation-induced lung fibrosis (RILF). To date, corticosteroids are mainly used to control RP in the clinic, while RILF leads to progressive alveolar structural disorders and irreversible pulmonary fibrous tissue remodelling, which eventually causes respiratory failure. There is currently no effective drug available to reverse RILF. ${ }^{6}$

Macrophages are highly malleable, and their functional phenotypes depend on different microenvironments. After exposure to Toll-like receptor (TLR) ligands, macrophages experience a phenotype known as classically activated macrophages or M1 macrophages, which can produce high levels of pro-inflammatory cytokines, such as tumour necrosis factor- $\alpha$ (TNF- $\alpha$ ), interleukin- 6 (IL-6) and inducible nitric oxide synthase (iNOS). In contrast, alternately activated macrophages or M2 macrophages are produced in response to cytokines such as IL-4 and IL-13 and highly express M2 macrophage-associated inflammatory factors, such as chitinase 3-like 3 (YM-1) and arginase-1 (ARG-1). ${ }^{7}$ M1 macrophages have been shown to prevent the development of pulmonary fibrosis, and M2 macrophages are the most prominent type of macrophage in pulmonary fibrosis. ${ }^{8}$ Therefore, the balanced transition from M1 macrophages that promote inflammation to $M 2$ macrophages that promote fibrosis and wound healing is one of the important reasons for the development of pulmonary fibrosis after radiation.

Pirfenidone (PFD) is a multipotent pyridone analog that was discovered by the MARNAC Company in 1974. The antifibrotic effect of PFD was first found in a bleomycin-induced idiopathic pulmonary fibrosis (IPF) animal model in 1995. ${ }^{9}$ Later, studies have shown that PFD could inhibit fibrosis by downregulating the expression of $\mathrm{fi}$ brogenic growth factors, inhibiting the production and release of inflammatory cytokines and reducing the occurrence of lipid peroxidation and oxidative stress injury. ${ }^{10-14}$ PFD has a significant inhibitory effect on pulmonary fibrosis and fibrosis in other organs and is a broad-spectrum antifibrotic drug. A number of phase III clinical studies have shown that PFD can significantly delay the decline in forced vital capacity (FVC) in patients with IPF and significantly reduce the mortality of IPF. ${ }^{15,16}$ Based on these data, PFD became the first drug approved by the FDA to treat IPF in 2014. The pathological and physiological process of RILF is similar to that of IPF and involves the early inflammatory reaction, lung parenchymal injury, alveolar repair and interstitial fibrosis. A previous study reported that PFD could downregulate the expression of transforming growth factor- $\beta 1$ (TGF- $\beta 1$ ) in lung tissue, leading to the inhibition of RILF progression, but the deeper mechanism has not been elucidated. ${ }^{17}$

In the present study, we investigated the protective effects of PFD on RILF in vivo and in vitro. We demonstrated that PFD could reduce the polarization of M2 macrophages and inhibit the activation of TGF- $\beta 1 /$ Smad3 signalling of alveolar epithelial cells (AECs) and vascular endothelial cells (VECs) by ionizing radiation. PFD was also involved in the regulation of AECs and macrophages. Thus, PFD has therapeutic potential for patients with RILF.

\section{2 | MATERIALS AND METHODS}

\subsection{Animals and reagents}

10- to 12-week-old inbred C57BL/6 female mice (body weight 18$20 \mathrm{~g}$ ) were provided by Shanghai Xipuer Bikai Experimental Animal Co., Ltd. (production licence: SCXK 2013-0016) and housed in the SPF animal breeding room of the Experimental Animal Center of Zhejiang Chinese Medical University. The mice were housed six per cage under standard conditions and had free access to food and water. The mice were transferred in and out of the SPF animal room using dedicated sealed transfer boxes with air filtration.

\section{2 | Irradiation and PFD treatment}

40 female C57BL/6 mice were randomized into four groups: the negative control (NC, normal saline) group, radiation alone (RT) group, PFD alone (PFD group) and radiation plus PFD (RT + PFD) group. For radiation exposure, the mice were anaesthetized using sodium pentobarbital ( $40 \mathrm{mg} / \mathrm{kg}$, intraperitoneally) and received a single $50 \mathrm{~Gy}$ dose of whole-lung $\mathrm{X}$-ray delivered by a small animal radiation research platform (4 Gy/min; SSD = $333 \mathrm{~mm}$; XStrahl). Pirfenidone was obtained from Beijing Kangdini Pharmaceutical Co., Ltd. and dissolved in $0.5 \%$ carboxymethyl cellulose solution (CMC, vehicle) at a concentration of $20 \mathrm{mg} / \mathrm{ml}$, which was given orally by gavage at a dose of $300 \mathrm{mg} / \mathrm{kg} /$ day every day based on published data. ${ }^{18,19}$

\section{3 | Histology}

All mice were fixed on the operating table and euthanized by femoral artery exsanguination at day 150 under sodium pentobarbital anaesthesia (40 mg/kg, intraperitoneally), and all efforts were made to minimize animal suffering. The right lung tissues were stored at $-80^{\circ} \mathrm{C}$ for qRT-PCR and Western blot analysis, and the left lung 
tissues were fixed in $4 \%$ paraformaldehyde, dehydrated and embedded in paraffin. Then, the lung tissues were sectioned into 4- $\mu \mathrm{m}$ slices and stained with HE. Masson's trichrome was used to evaluate fibrosis based on 10 fields of view in each section. Five section was examined per lung, and five fields were randomly selected for each section. The severity of fibrosis in each field of the lung was assessed as the mean severity score using a semiquantitative grading system described by Ashcroft et al. ${ }^{20}$

After deparaffinization in xylene, hydration with graded alcohol and antigen retrieval, the tissue sections were placed in $3 \%$ hydrogen peroxide $\left(\mathrm{H}_{2} \mathrm{O}_{2}\right)$ for $10 \mathrm{~min}$ at room temperature to inactivate endogenous peroxidases. The slides were washed three times in PBS, blocked with $2 \%$ bovine serum albumin (BSA, cat. no. B2064, Sigma) for $30 \mathrm{~min}$ at room temperature and incubated with primary antibodies against collagen I (1:200, cat. no. ab34710, Abcam), collagen IV (1:200, cat. no. ab6586, Abcam), CD79b (1:200, cat. no. 134147, Abcam), CD68(1:200, cat. no. 31630, Abcam) and CD3 (1:200, cat. no. Ab16669, Abcam) at $4^{\circ} \mathrm{C}$ overnight. The slides were then washed with PBS and incubated with HRP-conjugated secondary antibodies (1:200, Beyotime) for $60 \mathrm{~min}$ at $37^{\circ} \mathrm{C}$. The slides were then washed in PBS three times, followed by detection with Dako REALTM EnVisionTM (DAB, cat. no. PW017, Sangon Biotech) and counterstaining with haematoxylin.

For immunohistochemical (IHC) scoring, positive reactions were defined as those showing brown signals. One section was examined per lung, and five fields were randomly selected and observed under a light microscope. The intensity was scored as follows: 0: negative; 1: weak; 2: moderate; and 3: strong. The frequency of positive cells was defined as follows: 0: less than 5\%; 1: $5 \%-25 \%$; 2: $26 \%-50 \%$;
TABLE 1 Primer sequences used to quantitate gene expression

\begin{tabular}{|c|c|}
\hline Gene & Sequence $\left(5^{\prime}\right.$ to $\left.3^{\prime}\right)$ \\
\hline \multirow[t]{2}{*}{ TNF- $\alpha$} & Forward: AAGGCCGGGGTGTCCTGGAG \\
\hline & Reverse: AGGCCAGGTGGGGACAGCTC \\
\hline \multirow[t]{2}{*}{ iNOS } & Forward: CCCTTCCGAAGTTTCTGGCAGCAGCG \\
\hline & Reverse: GGCTGTCAGAGCCTCGTGGCTTTGG \\
\hline \multirow[t]{2}{*}{ Arg-1 } & Forward: TCATGGAAGTGAACCCAACTCTTG \\
\hline & Reverse: TCAGTCCCTGGCTTATGGTTACC \\
\hline \multirow[t]{2}{*}{ YM-1 } & Forward: GGATGGCTACACTGGAGAAA \\
\hline & Reverse: AGAAGGGTCACTCAGGATAA \\
\hline \multirow[t]{2}{*}{ CCL2 } & Forward: TTAAAAACCTGGATCGGAACCAA \\
\hline & Reverse: GCATTAGCTTCAGATTTACGGGT \\
\hline \multirow[t]{2}{*}{ CXCL10 } & Forward: AAGTGCTGCCGTCATTTTCT \\
\hline & Reverse: TTCATCGTGGCAATGATCTC \\
\hline \multirow[t]{2}{*}{ CXCL16 } & Forward: CCTTGTCTCTTGCGTTCTTCC \\
\hline & Reverse: TCCAAAGTACCCTGCGGTATC \\
\hline \multirow[t]{2}{*}{ CXCL5 } & Forward: TGCGTTGTGTTTGCTTAACCG \\
\hline & Reverse: CTTCCACCGTAGGGCACTG \\
\hline \multirow[t]{2}{*}{ CXCL1 } & Forward: CTGGGATTCACCTCAAGAACATC \\
\hline & Reverse: CAGGGTCAAGGCAAGCCTC \\
\hline \multirow[t]{2}{*}{ GM-CSF } & Forward: GGCCTTGGAAGCATGTAGAGG \\
\hline & Reverse: GGAGAACTCGTTAGAGACGACTT \\
\hline \multirow[t]{2}{*}{$\beta$-Actin } & Forward: GCATTGCTGACAGGATGCAG \\
\hline & Reverse: CCTGCTTGCTGATCCACATC \\
\hline
\end{tabular}

3: $51 \%-75 \%$; and 4: greater than $75 \%$. The IHC total score was calculated as the product of the intensity and frequency scores (0-12)
A
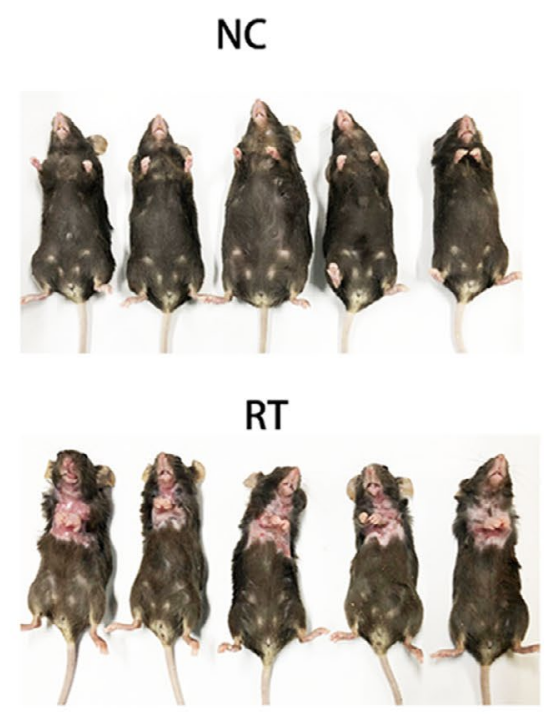

PFD
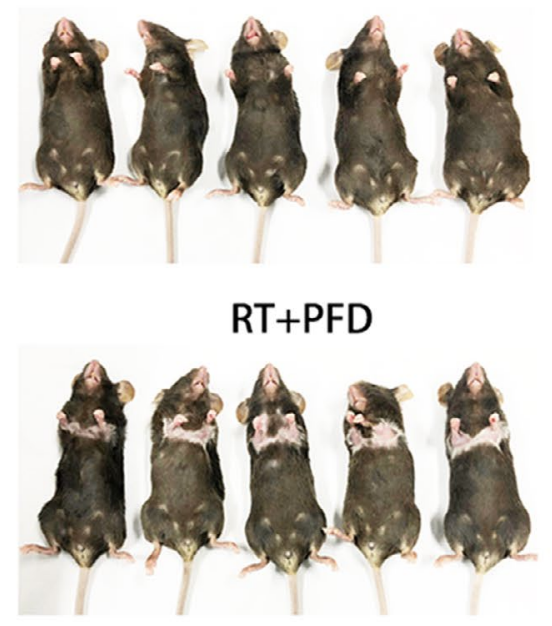

B

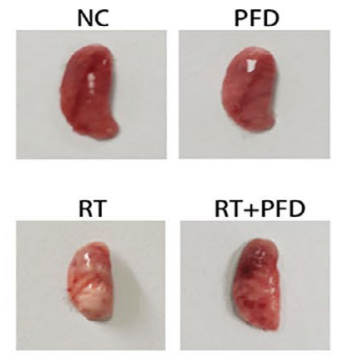

C

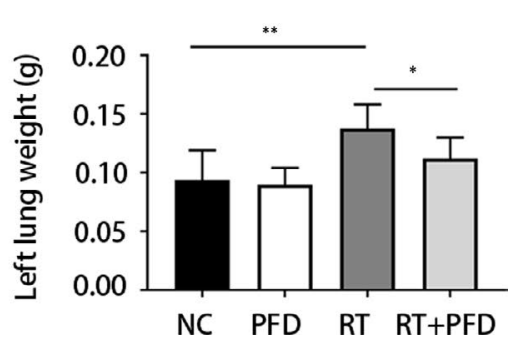

FIGURE 1 Pirfenidone attenuates pulmonary fibrosis induced by whole-lung radiation. A, Photographs of mice in the four groups after 84 days of treatment. B, Photographs of the lung tissue in the four groups. C, The mean left lung weights of mice in the four groups ( $n=5$ per group). The values are the means $\pm \mathrm{SD},{ }^{*} p<0.05,{ }^{* *} p<0.01$ 
and was performed by trained scorers blind. After whole section examination, the IHC score was calculated as the mean total IHC score of all fields.

\subsection{Immunofluorescence staining of lung tissue}

Immunofluorescence (IF) analysis was performed on 4- $\mu$ m-thick lung sections that had been dewaxed with xylene and hydrated using sequential ethanol (100\%, 95\%, $85 \%$ and $75 \%$ ) and distilled water. Antigen retrieval was performed by heating the sections in $0.1 \%$ sodium citrate buffer ( $\mathrm{pH}$ 6.0). Then, the specimens were washed with PBS and blocked with 10\% FBS to eliminate nonspecific fluorescence. Immunofluorescence staining was performed using antibodies against CD68 (1:200, cat. no. 31630, Abcam) and CD163 (1:200, cat. no. 182422, Abcam), and the cell preparations were incubated with DyLight 488/647-labelled secondary antibodies (1:200, cat. no. 150077/ab150115, Abcam).

\section{5 | Quantitative reverse transcription- polymerase chain reaction}

Total RNA was extracted with RNAiso Plus reagent (cat. no. 10895-2, Takara). qRT-PCR was performed using SYBR ${ }^{\circledR}$ Premix Ex Taq II (cat. no. RR820A, Takara), after reverse transcribing $1 \mu \mathrm{g}$ RNA with PrimeScript ${ }^{\mathrm{TM}}$ RT Master Mix (cat. no. RR036A-2, Takara). qRTPCR analysis of the resulting CDNA was performed in triplicate with gene-specific primers on a 7500 Fast Real-time PCR system (Applied Biosystems, Thermo Fisher Scientific). The qRT-PCR was carried out with the following conditions: denaturation at $94^{\circ} \mathrm{C}$ for $2 \mathrm{~min}$, followed by 40 cycles of $94^{\circ} \mathrm{C}$ for $15 \mathrm{~s}$ and $62^{\circ} \mathrm{C}$ for $40 \mathrm{~s}$. Gene expression levels were normalized to $\beta$-actin by the $2^{-\Delta \Delta \mathrm{Ct}}$ method and were determined relative to control samples. The primers for qRTPCR are listed in Table 1.

\subsection{Western blotting}

Protein samples $(40 \mu \mathrm{g})$ were mixed with SDS-PAGE loading buffer and boiled at $100^{\circ} \mathrm{C}$ for $5 \mathrm{~min}$. After electrophoresis, the proteins were transferred to PVDF membranes (cat. no. IPVH00010, Millipore Biotechnology). The membranes were blocked with $5 \%$ BSA for $60 \mathrm{~min}$ at room temperature. The membranes were incubated with primary antibodies against ARG-1 (1:1000, cat. no. ab91279, Abcam), YM-1 (1:1000, cat. no. ab192029, Abcam), TGF$\beta 1$ (1:1000, cat. no. ab92486, Abcam), p-Smad3 (1:1000, cat. no. ab52903, Abcam), Smad3 (1:1000, cat. no. ab40854, Abcam), NF-kB p50 (1:1000, cat. no. Sc-8414) and $\beta$-actin (1:5000, cat. no. A2228, Sigma) in $5 \% \mathrm{BSA}$ overnight at $4^{\circ} \mathrm{C}$. Afterwards, membranes were washed three times with TBS containing 0.5\% Tween 20 (TBST) for 10 min each time at room temperature and then incubated with secondary antibodies (1:5000, cat. no. ab150077, Abcam or 1:5000, cat. no. ab150113, Abcam) for $60 \mathrm{~min}$ at room temperature. After three additional washes with TBST, immunoreactive bands were visualized using enhanced chemiluminescent reagent (ECL, cat. no. WBKLS0500, Millipore Biotechnology) and quantified by ImageJ V1.8.0 (National Institutes of Health) analysis software.

\subsection{Cell culture}

Bone marrow cells were obtained by flushing femurs from 6- to 8-week-old mice and differentiating the cells (7 days) in Dulbecco's modified Eagle's medium (DMEM, HyClone) supplemented with $30 \mathrm{ng} / \mathrm{ml}$ macrophage colony-stimulating factor (M-CSF, PeproTech), $10 \%$ foetal bovine serum (FBS, Gibco) and antibiotics (Wonder Biotech).

The mouse macrophage line (RAW264.7 cells) was purchased from the Cell Bank of the Chinese Academy of Sciences. RAW264.7 cells were maintained in DMEM supplemented with $10 \%$ FBS and antibiotics. Cell cultures were maintained at $37^{\circ} \mathrm{C}$ in a humidified atmosphere containing $5 \% \mathrm{CO}_{2}$. The medium was changed every 3 days until the culture reached $90 \%$ confluence. For experiments, cells were suspended in culture medium at a density of $1 \times 10^{6}$ cells/ $\mathrm{ml}$. Cells at passages 3-5 were used for all experiments.

MLE-12 cells and PMVECs were obtained from the Cell Bank of the Chinese Academy of Sciences. MLE-12 cells and PMVECs were maintained in DMEM supplemented with $10 \%$ FBS and antibiotics. Cell cultures were maintained at $37^{\circ} \mathrm{C}$ in a humidified atmosphere containing $5 \% \mathrm{CO}_{2}$. The medium was changed every 3 days until the culture had reached $90 \%$ confluence. For experiments, cells were suspended in culture medium at a density of $1 \times 10^{6}$ cells $/ \mathrm{ml}$. Cells at passages 3-5 were used for all experiments.

\section{8 | Macrophage polarization and PFD treatment}

Pirfenidone was dissolved in dimethyl sulfoxide (DMSO, Sigma) and used at final concentrations of $1,10,100$ or $1000 \mu \mathrm{g} / \mathrm{ml}$ (The DMSO was used in the 0 PFD as control.).

RAW264.7 cells and bone marrow-derived macrophages (BMDMs) were cultured in DMEM supplemented with PFD for $24 \mathrm{~h}$ before treatment with chemokines to promote macrophage polarization. After $24 \mathrm{~h}$ of PFD incubation, the cells were stimulated with $10 \mathrm{ng} / \mathrm{ml} \mathrm{IL-4} \mathrm{(PeproTech)} \mathrm{and} 10 \mathrm{ng} / \mathrm{ml} \mathrm{IL-13} \mathrm{(PeproTech)} \mathrm{to} \mathrm{promote}$ $\mathrm{M} 2$ polarization. After an additional $24 \mathrm{~h}$, cell supernatants were collected for ELISA analysis, and the cells were washed twice with PBS and harvested in RIPA or RNAiso Plus reagent for subsequent analysis.

\section{9 $\mid$ MLE-12 and PMVECs and PFD treatment}

MLE-12 cells and PMVECs were cultured in DMEM with 10\% FBS supplemented with PFD for $24 \mathrm{~h}$. After $24 \mathrm{~h}$ of PFD incubation, fresh medium was added, and the cells were stimulated with $12 \mathrm{~Gy} \mathrm{X}$-ray 
for an additional 24 h. Cell supernatants were collected for ELISA analysis, and the cells were washed twice with PBS and harvested in RIPA buffer for subsequent analysis.

\subsection{0 | MTT analysis of cell viability}

Cells were incubated in the presence of different concentrations of PFD. MTT (3-[4, 5-dimethylthiazol-2-yl]-2,5-diphenyl tetrazolium bromide; $2 \mathrm{mg} / \mathrm{ml}$ ) was added to the wells and incubated for $3 \mathrm{~h}$ at $37^{\circ} \mathrm{C}$. The reaction product formazan was extracted with DMSO, and the absorbance was measured at $540 \mathrm{~nm}$ as previously described. ${ }^{21}$

\subsection{1 | Enzyme-linked immunosorbent assay}

The levels of TGF- $\beta 1$ (cat. no. DY1679-05, R\&D), CCL2 (cat. no. DY479-05, R\&D) and CXCL1 (cat. no. DY453-05, R\&D) in the cell culture supernatant of the different treatment groups were measured by their respective ELISA kits. The optical density of each sample was measured at $450 \mathrm{~nm}$ using a Spectra Max 190 microplate reader.

\subsection{2 | Flow cytometry}

Macrophages in the different treatment groups were digested and washed with PBS three times. Cell suspensions were adjusted to $10^{6} / \mathrm{ml}$. Antibodies against F4/80 (cat. no. 11-480-82, eBioscience) and CD206 (cat. no. 12-2061-82, eBioscience, USA) were added and incubated at room temperature for $30 \mathrm{~min}$, and the cells were analysed by flow cytometry (FACS Verse assay, BD Biosciences).

\subsection{3 | Immunofluorescence staining of macrophages}

Macrophages were cultured in 12-well plates containing glass slides and were then washed with PBS and fixed with $4 \%$ paraformaldehyde for $30 \mathrm{~min}$. After permeabilization with $0.1 \%$ Triton $\mathrm{X}-100$ for $10 \mathrm{~min}$, the specimens were washed with PBS and then blocked with 10\% FBS to eliminate nonspecific fluorescence. Immunofluorescence staining was performed using ARG-1 (1:200, cat. no. ab91279, Abcam), YM-1 (1:200, cat. no. ab192029, Abcam) and CD163 (1:200, cat. no. 182422, Abcam) primary
A

HE
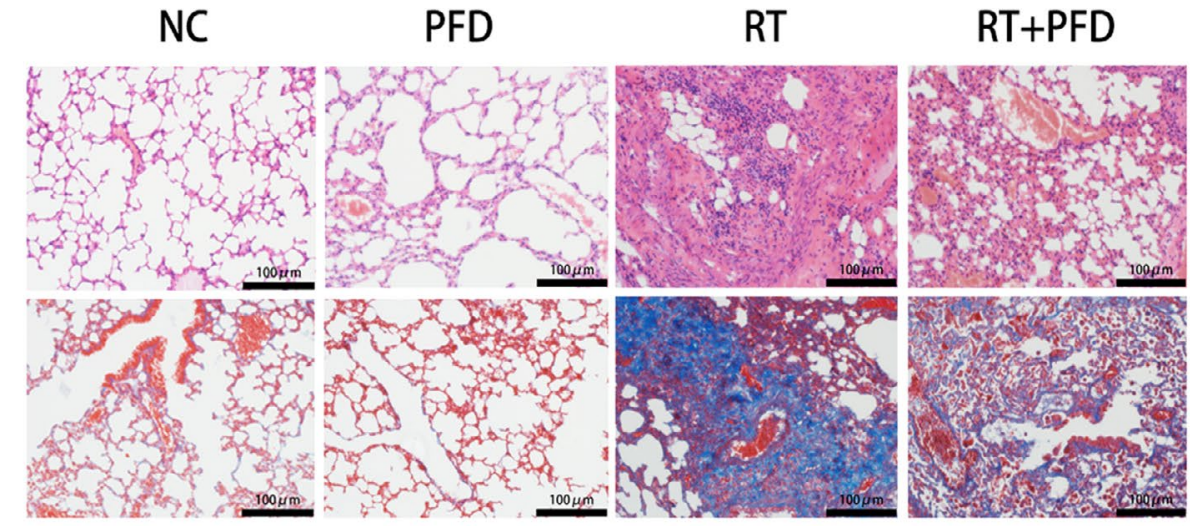

B

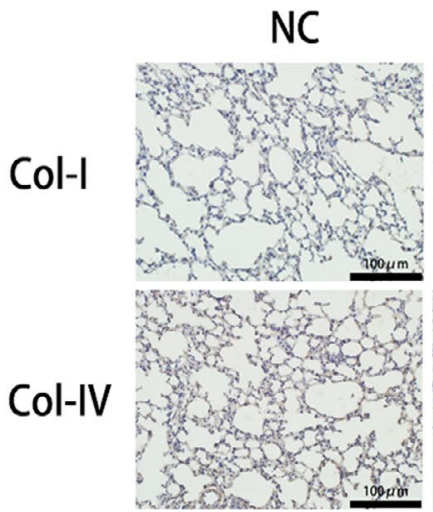

PFD

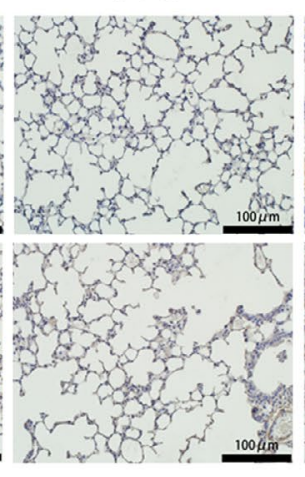

RT

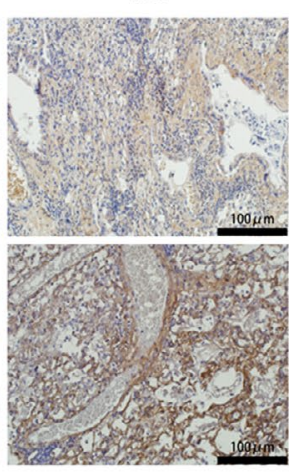

$\mathrm{RT}+\mathrm{PFD}$

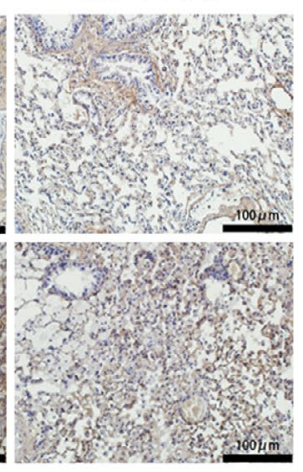

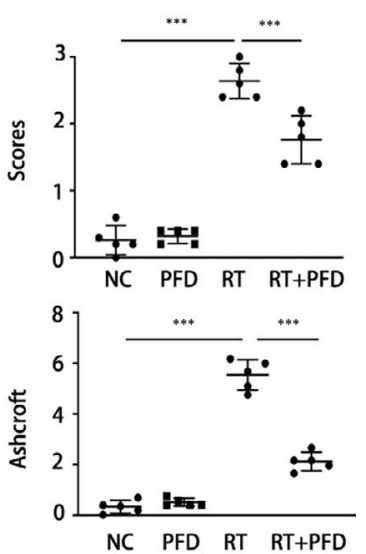

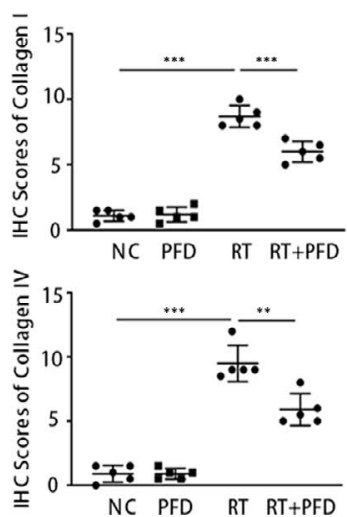

FIGURE 2 Pirfenidone effectively inhibited alveolar inflammation, pulmonary fibrosis and collagen deposition induced by lung irradiation. A, HE and Masson staining of lung tissues in the four groups and semiquantitative analysis of the degree of pulmonary fibrosis. The values are the means \pm SD, ${ }^{* *} p<0.01,{ }^{* * *} p<0.001$. B, IHC staining of collagen I and collagen IV in lung tissue from the four groups and semiquantitative analysis of collagen I and collagen IV expression. Scale bar $=100 \mu \mathrm{m}$. The values are the means \pm SD, ${ }^{* *} p<0.01$, ${ }^{* * *} p<0.001$ 
A

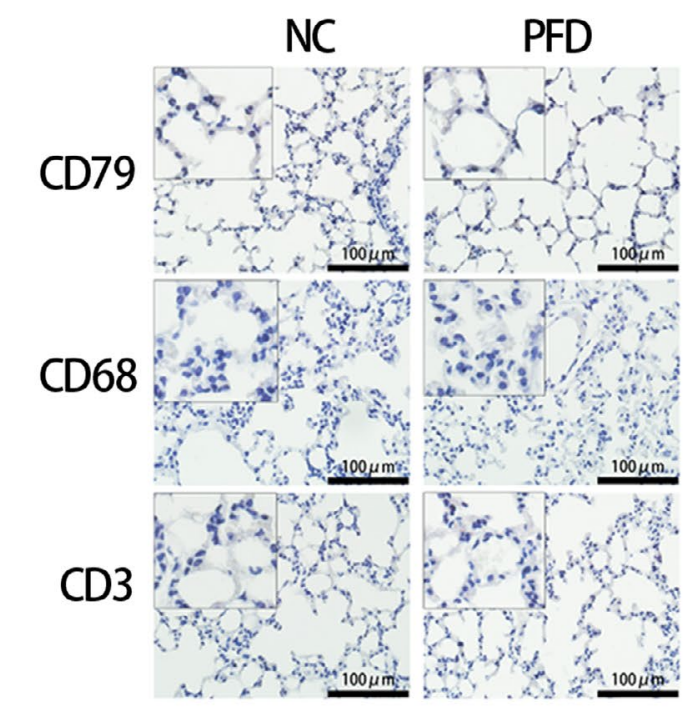

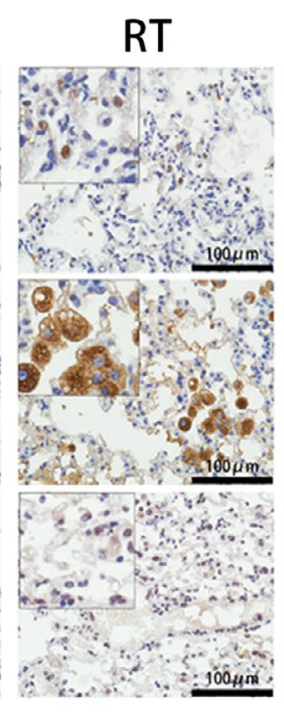

B
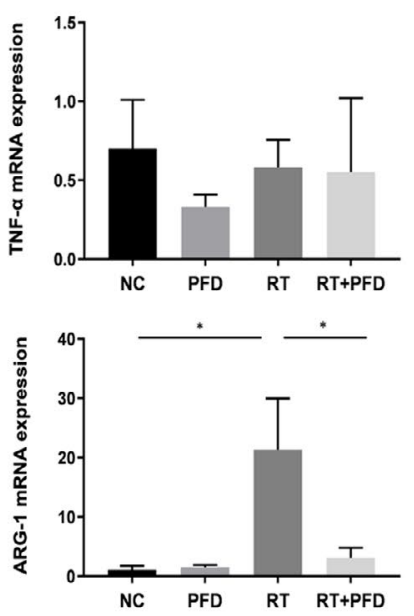
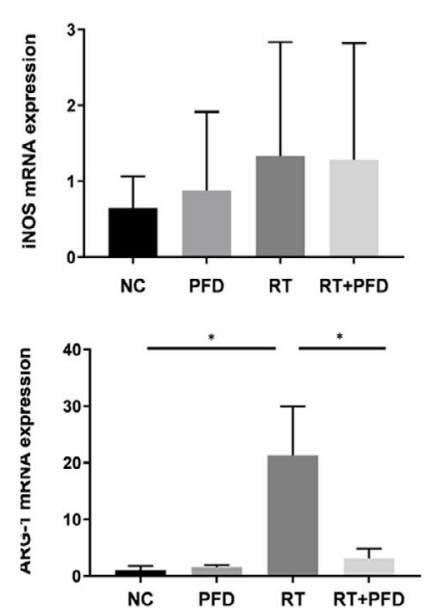

$\mathrm{RT}+\mathrm{PFD}$
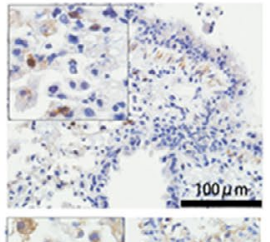
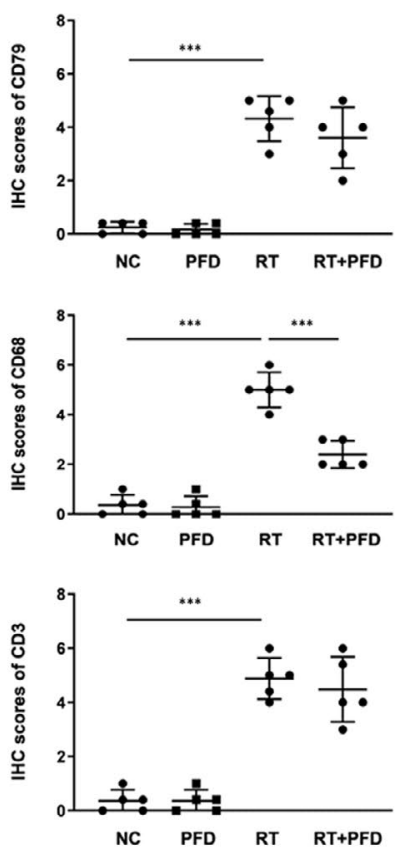

C

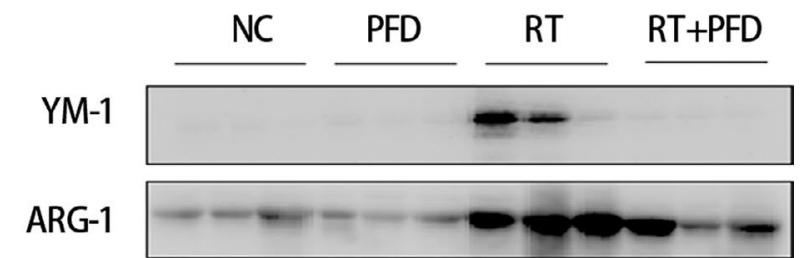

B-Actin
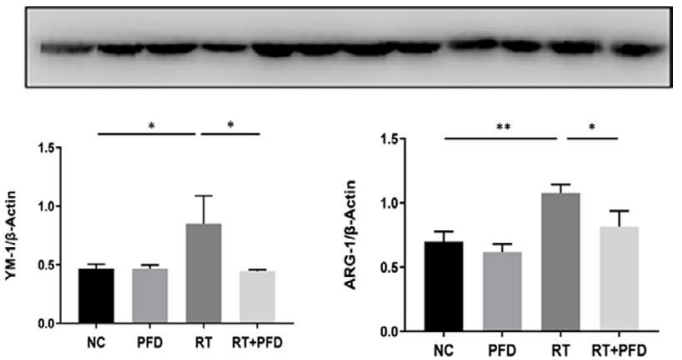

FIG URE 3 Pirfenidone inhibits ionizing radiation-induced M2 polarization. A, The expression of CD68, CD79 and CD3 in the lung tissue of mice in the different treatment groups was determined by IHC analysis. Scale bar $=100 \mu \mathrm{m}$. B, qRT-PCR was used to measure the expression of ARG-1, YM-1, iNOS and TNF- $\alpha$ in the lung tissue of mice in the different treatment groups. ( $n=3$ per group). The values are the means $\pm \mathrm{SD},{ }^{*} p<0.05, \mathrm{C}$, Western blotting was used to measure the expression of ARG-1 and YM-1 in the lung tissue of mice in the different treatment groups. Data from individual animals ( $n=3$ per group). The values are the means $\pm \mathrm{SD},{ }^{*} p<0.05,{ }^{* *} p<0.01$

antibodies, and the cell preparations were incubated with DyLight 488/647-labelled secondary antibodies (1:200, cat. no. 150077/ ab150115, Abcam).

\subsection{4 | Macrophage migration assay}

RAW264.7 cells were seeded into the upper chamber of a Transwell insert (Corning Incorporated) at a density of $6 \times 10^{4}$ cells/well in $200 \mu \mathrm{l}$ of serum-free medium and placed on a 24 -well plate containing conditioned medium obtained from nonirradiated or irradiated MLE-12 cells. After $24 \mathrm{~h}$ of incubation, the cell suspension in the upper chamber was aspirated, and the upper surface of the filter was carefully cleaned with cotton buds. Cells that migrated through the polycarbonate membrane were fixed with $70 \%$ ethanol for 20 min and stained with $0.5 \%$ crystal violet for $15 \mathrm{~min}$. The membrane was cut away from the chamber, and migrated cells on the lower surface of the filter were counted in six representative fields with a microscope at $200 \times$ magnification.

\subsection{Cell co-culture}

MLE-12 cells were cultured in DMEM supplemented with $10 \%$ FBS, cell-free medium or $50 \%$ conditioned medium from RAW264.7 cells treated with PFD $(100 \mu \mathrm{g} / \mathrm{ml})$ and IL-4 and IL-13. 
A

RAW264.7
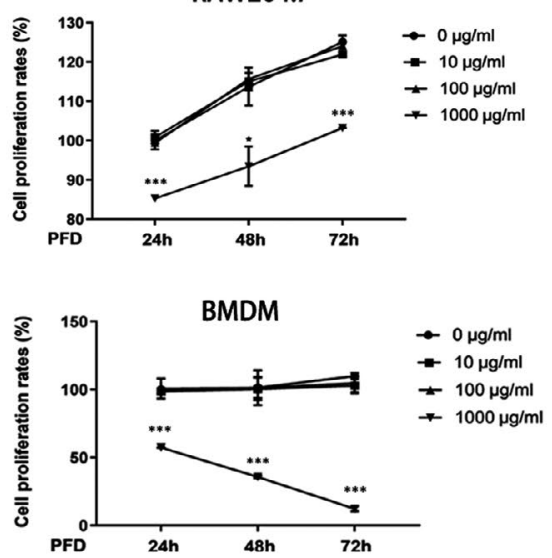

B

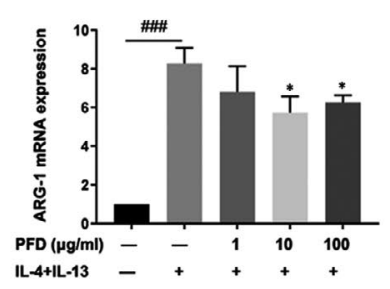

RAW264.7

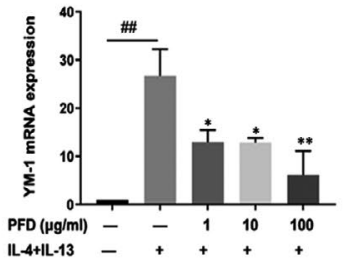

BMDM

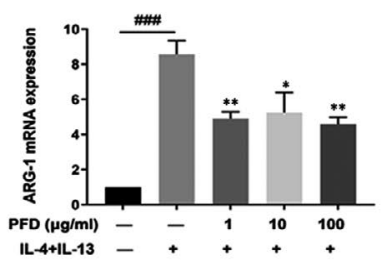

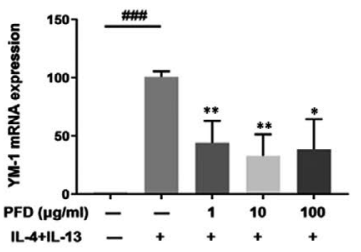

C

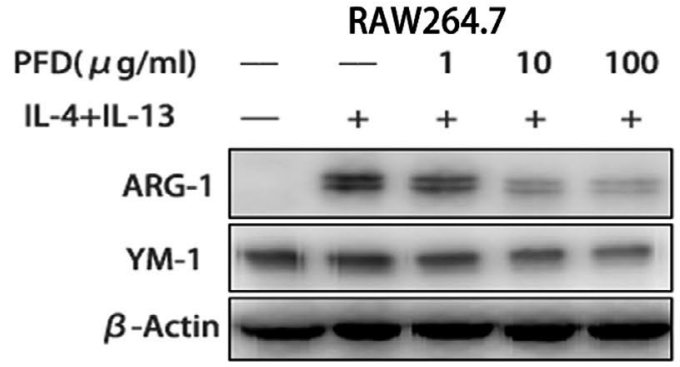

NF- $\kappa$ B p50

$\beta$-Actin

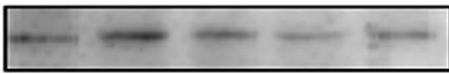

B-Actin

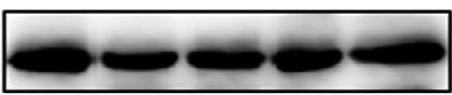

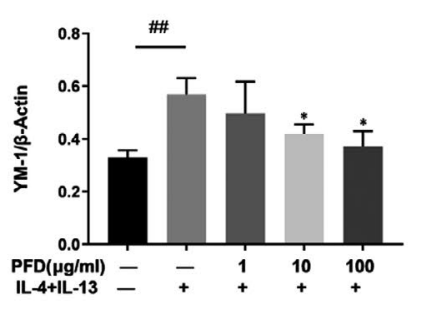

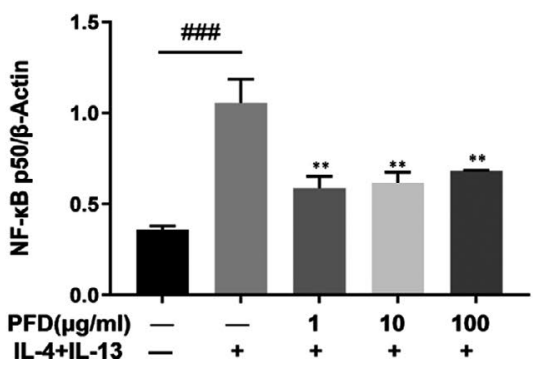

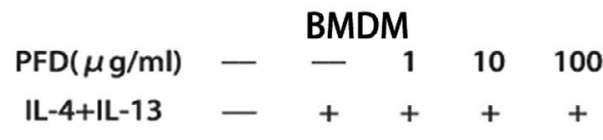
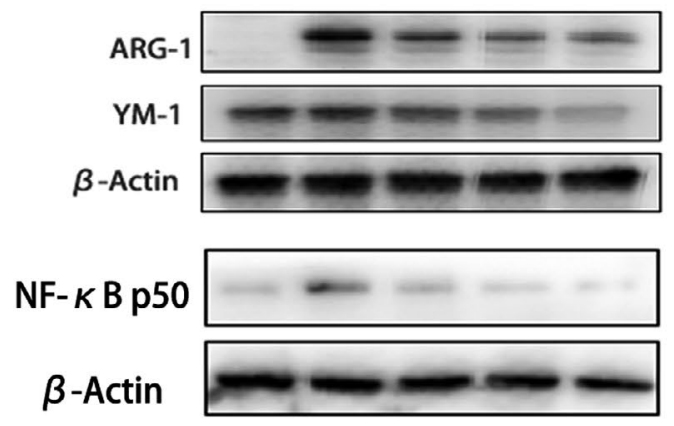
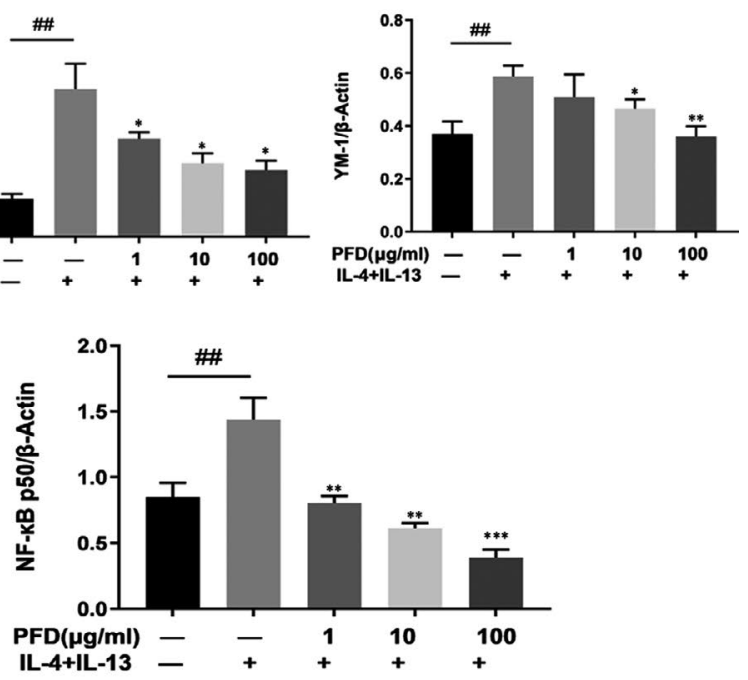

FIGURE 4 Pirfenidone inhibits the polarization of M2 macrophages by downregulating NF-kB p50 expression. A, Cytotoxic effects of PFD on RAW264.7 cells and BMDMs. Plots showing the effects of different concentrations of PFD on the growth of RAW264.7 cells and BMDMs during the indicated times. The values are the means \pm SD, ${ }^{*} p<0.05,{ }^{* *} p<0.01$, when comparing $1000 \mu \mathrm{g} / \mathrm{ml}$ with $0 \mu \mathrm{g} / \mathrm{ml}$. B, qRTPCR was used to analyse the quantitative mRNA expression of the M2 phenotypic markers ARG-1 and YM-1 in the 4 different treatment groups of RAW264.7 cells and BMDMs. The values are the means \pm SD, ${ }^{\# \#} p<0.01$ and ${ }^{\# \# \#} p<0.001$, when compared with the untreated group, ${ }^{*} p<0.05,{ }^{* *} p<0.01,{ }^{* * *} p<0.001$, when compared with the IL-4 + IL-13-stimulated group. C, Western blots and associated densitometry analysis of the protein expression of the M2 phenotypic markers ARG-1, YM-1 and NF-kB p50 in the 4 different treatment groups of RAW264.7 cells and BMDMs. The values are the means \pm SD, ${ }^{\# \#} p<0.01$ and ${ }^{\# \# \#} p<0.001$, compared with the untreated group, ${ }^{*} p<0.05,{ }^{* *} p<0.01,{ }^{* * *} p<0.001$ compared with the IL-4 + IL-13-stimulated group. The tests were repeated in three independent experiments 
A
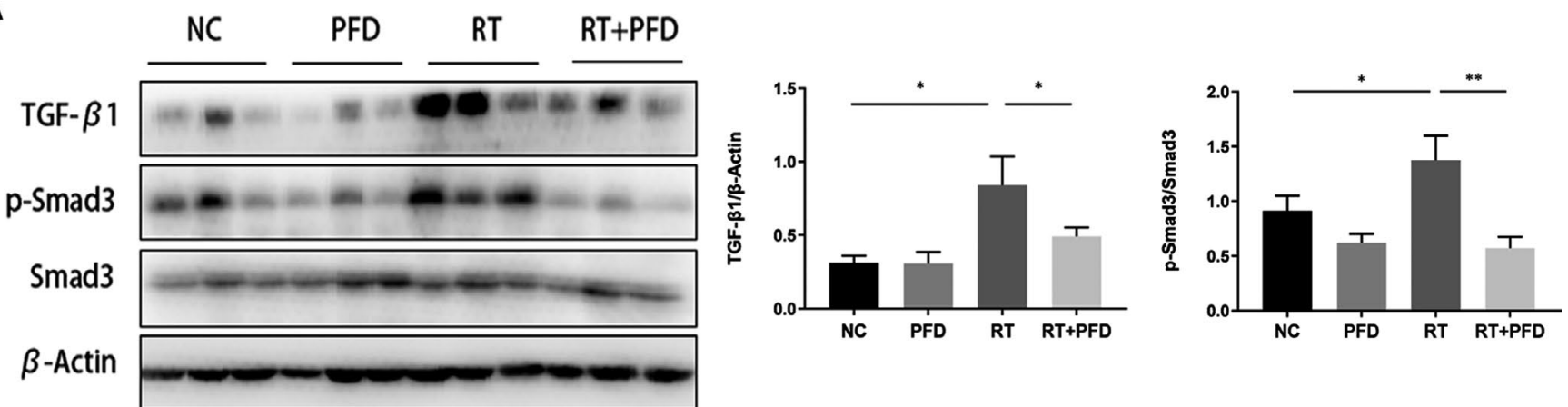

B

MLE-12

PMVEC
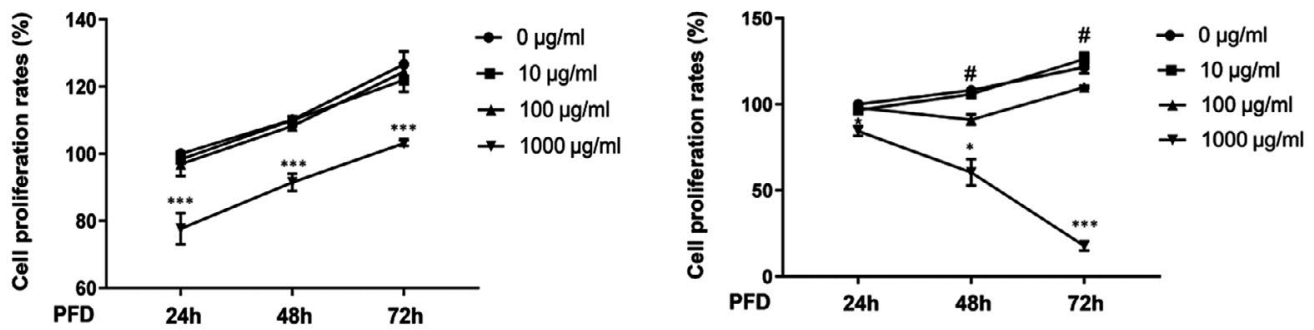

C

MLE-12
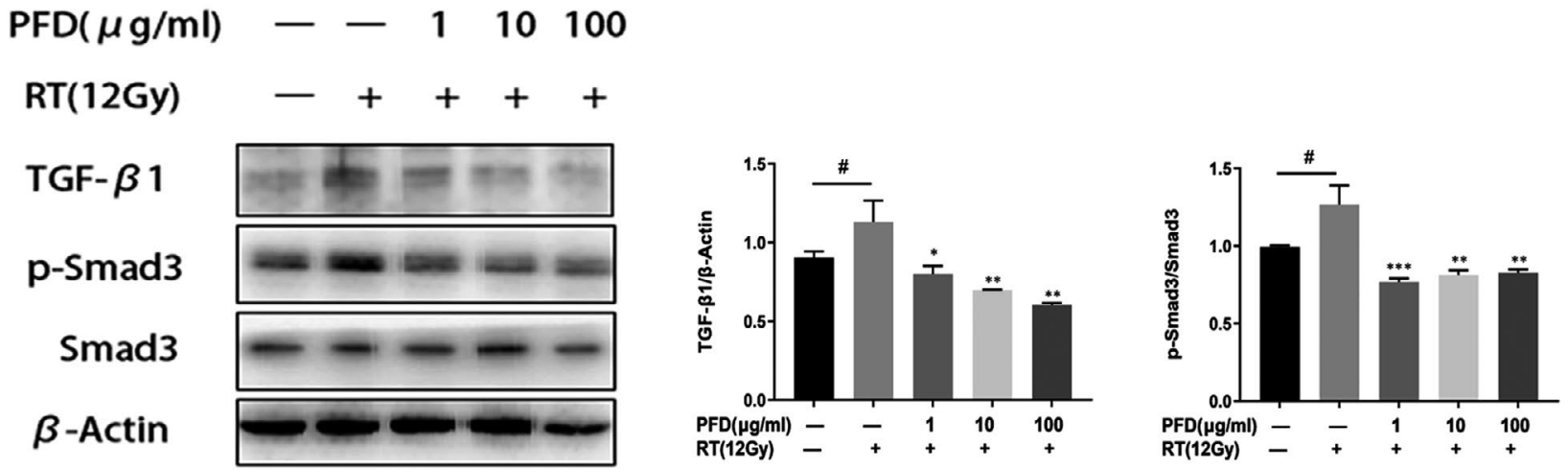

PMVEC
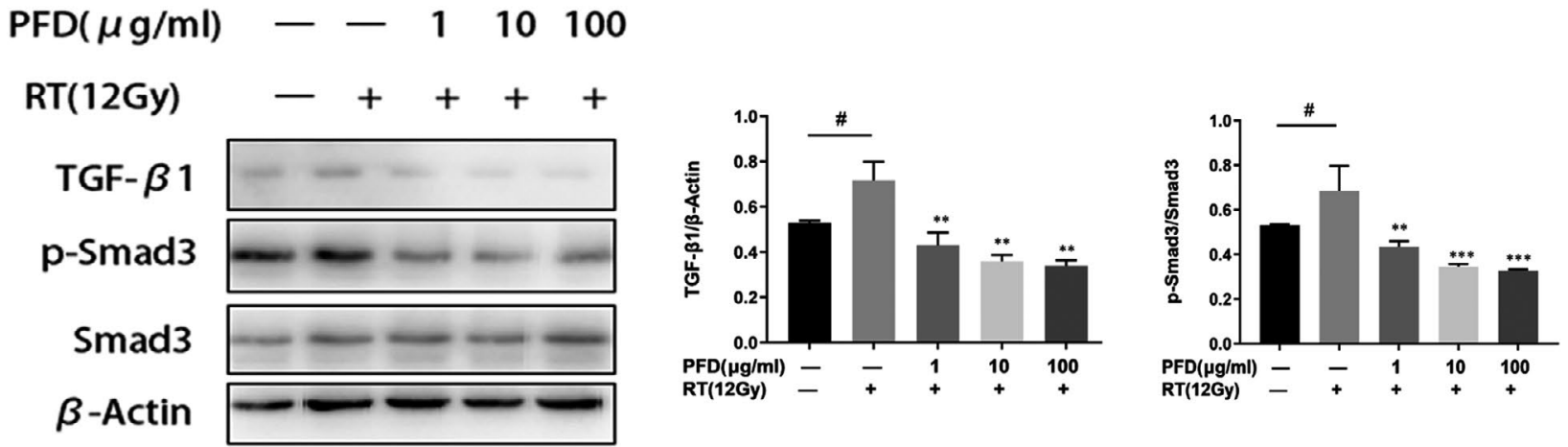

FIGURE 5 Pirfenidone inhibits irradiation-induced activation of the TGF- $\beta 1 /$ Smad3 signalling pathway in vivo and in vitro. A, The expression and quantitative analysis of TGF- $\beta 1, p$-Smad3, Smad3 and $\beta$-actin in lung tissue from the four different treatment groups. Data from individual animals ( $n=3$ per group); the values are the means $\pm S D,{ }^{*} p<0.05,{ }^{* *} p<0.01$. In Figures $3 C$ and $5 A$, we run the same four subgroups, NC, PFD, RT, RT + PFD and stain YM-1, ARG-1 (in Figure 3C) and TGF- $\beta 1$, p-Smad3, Smad3 (in Figure 5A). Therefore, the $\beta$-actin in Figure 3C and Figure 5A is the same band. B, Cytotoxic effects of PFD on the proliferation of MLE-12 cells and PMVECs. Plots showing the effects of different concentrations of PFD on the growth of MLE-12 cells and PMVECs over the indicated times. The values are the means \pm SD. MLE-12 cells: ${ }^{* * *} p<0.001,1000 \mu \mathrm{g} / \mathrm{ml}$ compared with $0 \mu \mathrm{g} / \mathrm{ml} \mathrm{PMVECs:}{ }^{* *} p<0.05,{ }^{* * *} p<0.001$, when comparing $100 \mu \mathrm{g} / \mathrm{ml}$ with $0 \mu \mathrm{g} / \mathrm{ml} ;{ }^{\# \# \#} p<0.001$, when comparing $1000 \mu \mathrm{g} / \mathrm{ml}$ with $0 \mu \mathrm{g} / \mathrm{ml}$. C. The expression and quantitative analysis of TGF- $\beta 1, \mathrm{p}$-Smad3, Smad3 and $\beta$-actin in MLE- 12 cells and PMVECs after RT and PFD treatment. The values are the means $\pm \mathrm{SD},{ }^{*} p<0.05$, compared with the untreated group, ${ }^{*} p<0.05,{ }^{* *} p<0.01$, ${ }^{* * *} p<0.001$, compared with the IL-4 + IL-13-stimulated group. The tests were repeated in three independent experiments 
After 24 h, MLE-12 cells were washed twice with PBS and harvested in sample buffer as described previously for subsequent Western blot analysis.

\subsection{6 | Statistical analysis}

Unless otherwise indicated, the data are presented as the means \pm SD of independent experiments. The statistical significance of the differences between two groups was analysed with Student's t-tests. The calculations were performed using Prism software for Windows (GraphPad Software).

\section{3 | RESULT}

\section{1 | Pirfenidone attenuates pulmonary fibrosis induced by whole-lung radiation}

After $50 \mathrm{~Gy}$ of whole-lung irradiation, the skin of mice in the RT and $\mathrm{RT}+$ PFD groups showed obvious lesions in the irradiated area, with the colour changing from black to white (Figure 1A). The skin lesions in the RT group were more serious than those in the RT + PFD group. In the RT group, the lung tissues became consolidated and white, with increased weight, and the morphological changes and increased weight were alleviated by PFD treatment (Figure 1B,C).

$\mathrm{HE}$ staining showed that the alveolar structure of the lung tissue in the NC and PFD groups was clear, with slender alveolar walls and intact capillary walls. In the RT group, the alveolar wall was severely thickened, and the alveolar cavity became obviously small, with many fibroblast aggregates, and patchy fibrosis appeared around blood vessels and the pulmonary interstitial area. After PFD treatment, the histological changes in the lung tissues were significantly alleviated compared with those of the RT group. Masson staining showed that the structure of the lung tissues in the NC and PFD groups was normal. In contrast, the alveolar wall in the RT group showed obvious destruction, with increased collagen deposition (blue area in Figure 2A), while collagen deposition was attenuated in the RT + PFD group (Figure 2A). The expression of collagen I and collagen IV in lung tissue was examined by IHC staining and showed significantly higher expression of collagen I and collagen IV in the RT group than in the NC and PFD groups. The expression of collagen I and collagen IV in the RT + PFD group was obviously decreased (Figure 2B).

\section{2 | Pirfenidone inhibits ionizing radiation- induced M2 macrophage polarization}

The IHC staining results showed that in the NC and PFD groups, the expression of CD68 (a marker of macrophages), CD79 (a marker of $B$ cells) and CD3 (a marker of T cells) was negative. However, in the RT group, CD68-positive, CD79-positive and CD3-positive immune cells were abundantly distributed in the RILF area. In the RT + PFD group, the proportion of CD68-positive immune cells decreased significantly in the lung tissue (Figure $3 \mathrm{~A}$ ). The IF staining results showed that the immune cells in the RT group were both CD68and CD163 (a marker of M2 macrophages)-positive. In the NC and PFD groups, there were no CD68- or CD163-positive cells. In the RT + PFD group, there were fewer CD68- and CD163-positive cells than in the RT group (Figure S1A). Compared with that of the NC and PFD groups, the expression of M2 macrophage-associated inflammatory factors ARG-1 and YM-1 in the RT group was upregulated, as determined by qRT-PCR. In the RT + PFD group, the expression of ARG-1 and YM-1 was downregulated. However, the expression of M1 macrophage-associated inflammatory factors TNF- $\alpha$ and iNOS in the four treatment groups was not significantly different (Figure 3B). The expression of these two proteins was the same when analysed by Western blotting (Figure $3 \mathrm{C}$ ).

\subsection{Pirfenidone inhibits the polarization of $\mathrm{M} 2$ macrophages by downregulating NF- $\mathrm{kB}$ p50}

After RAW264.7 cells were cocultured with BMDMs in the presence of $1000 \mu \mathrm{g} / \mathrm{ml}$ PFD, the proliferation of both cell types was significantly inhibited. PFD at a concentration of $100 \mu \mathrm{g} / \mathrm{ml}$ or less had no effect on the proliferation of either cell type (Figure 4A). PFD at a concentration of $100 \mu \mathrm{g} / \mathrm{ml}$ or less was used to further explore the effect of PFD on the polarity of M2 macrophages. We stimulated macrophages with $10 \mathrm{ng} /$ $\mathrm{ml} \mathrm{IL-4}$ and IL-13 for $24 \mathrm{~h}$ after pretreatment with $100 \mu \mathrm{g} / \mathrm{ml}$ PFD for $24 \mathrm{~h}$. Flow cytometry was used to measure the polarization of $\mathrm{F} 4 / 80^{+}(\mathrm{a}$ marker of macrophages)/CD206 ${ }^{+}$(a marker of M2 macrophages) M2 macrophages induced by the different treatments. Flow cytometric analysis showed that the proportion of $\mathrm{F} 4 / 80^{+} / \mathrm{CD} 206^{+}$macrophages was increased in IL-4- and IL-13-treated macrophages but decreased after PFD treatment (Figure S2A). qRT-PCR showed that the mRNA expression of ARG-1 and YM-1 in RAW264.7 cells and BMDMs induced by IL-4 and IL-13 was inhibited by PFD (Figure 4B). The expression of ARG-1, YM-1 and NF-kB p50 protein in RAW264.7 cells and BMDMs was measured by Western blotting and was also be inhibited by PFD (Figure 4C). In addition, immunocytochemical staining indicated that PFD could significantly inhibit IL-4- and IL-13-induced ARG-1, YM-1 and CD163 expression (Figure S2B).

\subsection{Pirfenidone inhibits activation of the TGF- $\beta 1$ / Smad3 signal pathway in vivo and in vitro}

The protein expression of TGF- $\beta 1$ and $p$-Smad3 in lung tissues was measured by Western blotting and showed that in the RT + PFD group (Figure $5 \mathrm{~A}$ ), the RT-induced expression levels of TGF- $\beta 1$ and $\mathrm{p}$-Smad 3 were downregulated by PFD (the $\beta$-actin in Figure $3 \mathrm{C}$ and Figure $5 \mathrm{~A}$ is the same band, because we run the same four subgroups). The cytotoxicity analysis showed that $1000 \mu \mathrm{g} / \mathrm{ml}$ PFD for more than $48 \mathrm{~h}$ significantly inhibited the proliferation of MLE-12 cells 
A

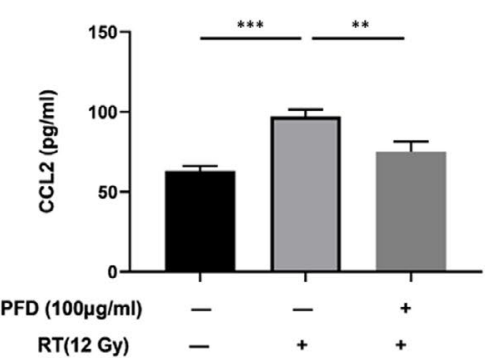

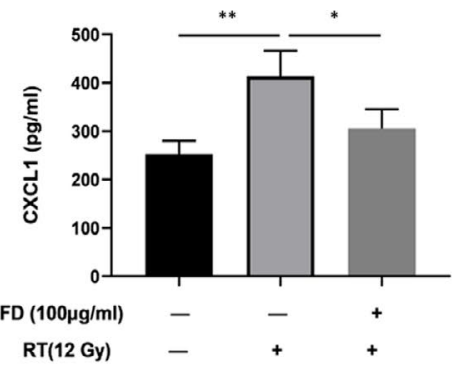

B

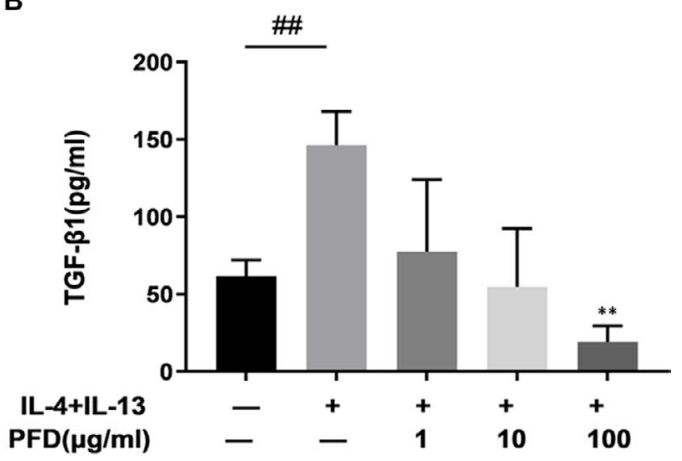

C
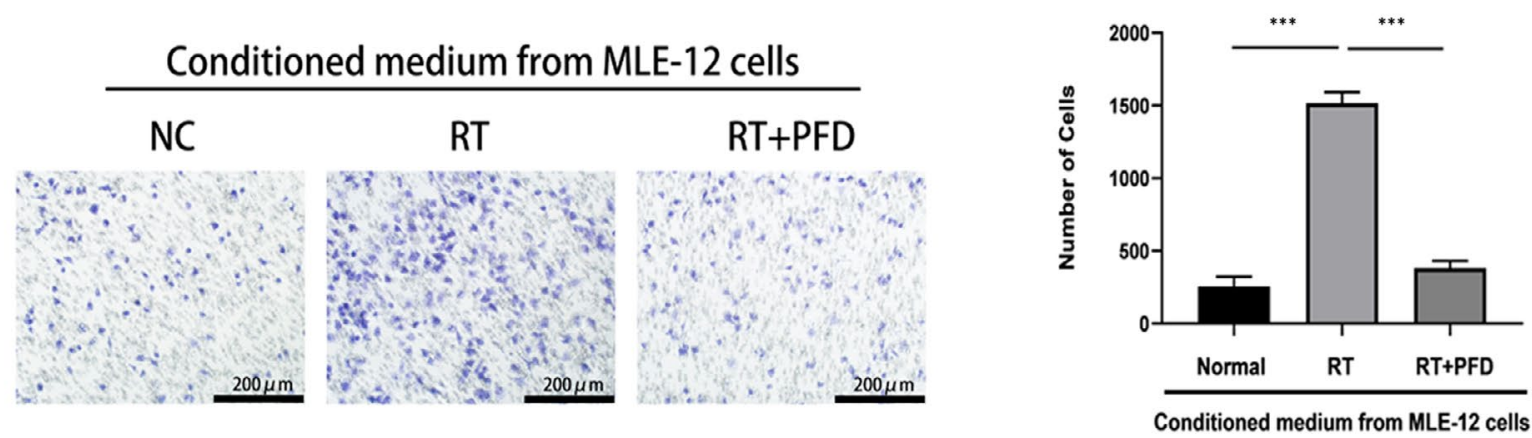

D

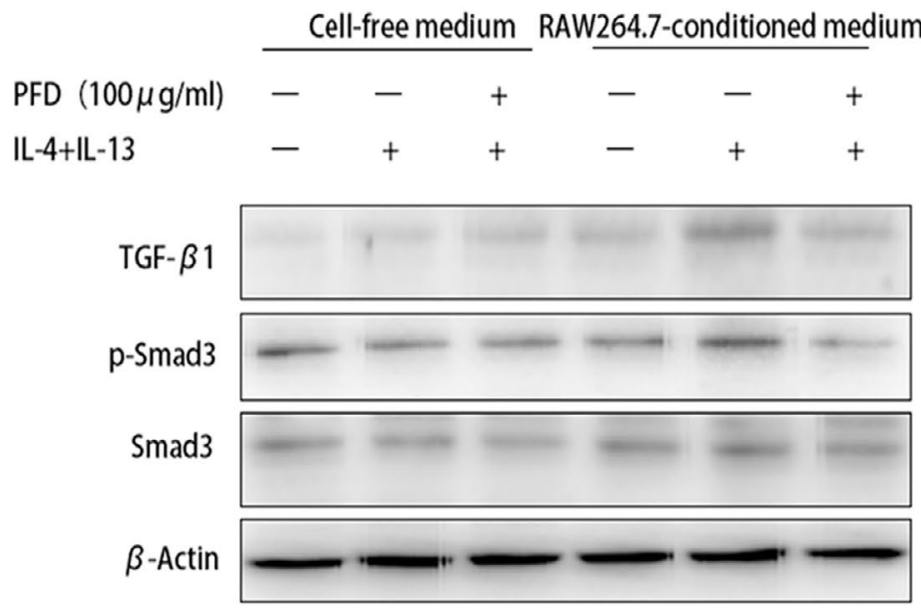

FIGURE 6 Pirfenidone is involved in the crosstalk between alveolar epithelial cells and macrophages. A, The protein levels of CCL2 and CXCL1 in MLE-12 cell culture supernatants were detected by ELISA after irradiation with 4 different doses. The values are the means $\pm \mathrm{SD},{ }^{*} p<0.05,{ }^{* *} p<0.01$, compared with $0 \mathrm{~Gy}$. B. The protein expression of TGF- $\beta 1$ in culture supernatants of RAW264.7 cells in the groups treated with IL-4 + IL-13 and PFD was measured by ELISA. The values are the means \pm SD, ${ }^{* *} p<0.01$, compared with 0 Gy. C, The migration of RAW264.7 cells was assessed in a Transwell assay. Representative images (left) and statistical analysis (right) show the migration of RAW264.7 cells induced by different conditioned media. Scale bar $=200 \mu \mathrm{m}$. The values are the means \pm SD, ${ }^{* * *} p<0.001$. D, The expression levels of $p$-Smad3, Smad3 and $\beta$-actin in MLE-12 cells cultured in conditioned media collected from RAW264.7 cells in the different treatment groups were analysed by Western blotting. The values are the means $\pm \mathrm{SD},{ }^{*} p<0.05,{ }^{* *} p<0.01,{ }^{* * *} p<0.001$. The tests were repeated in three independent experiments 


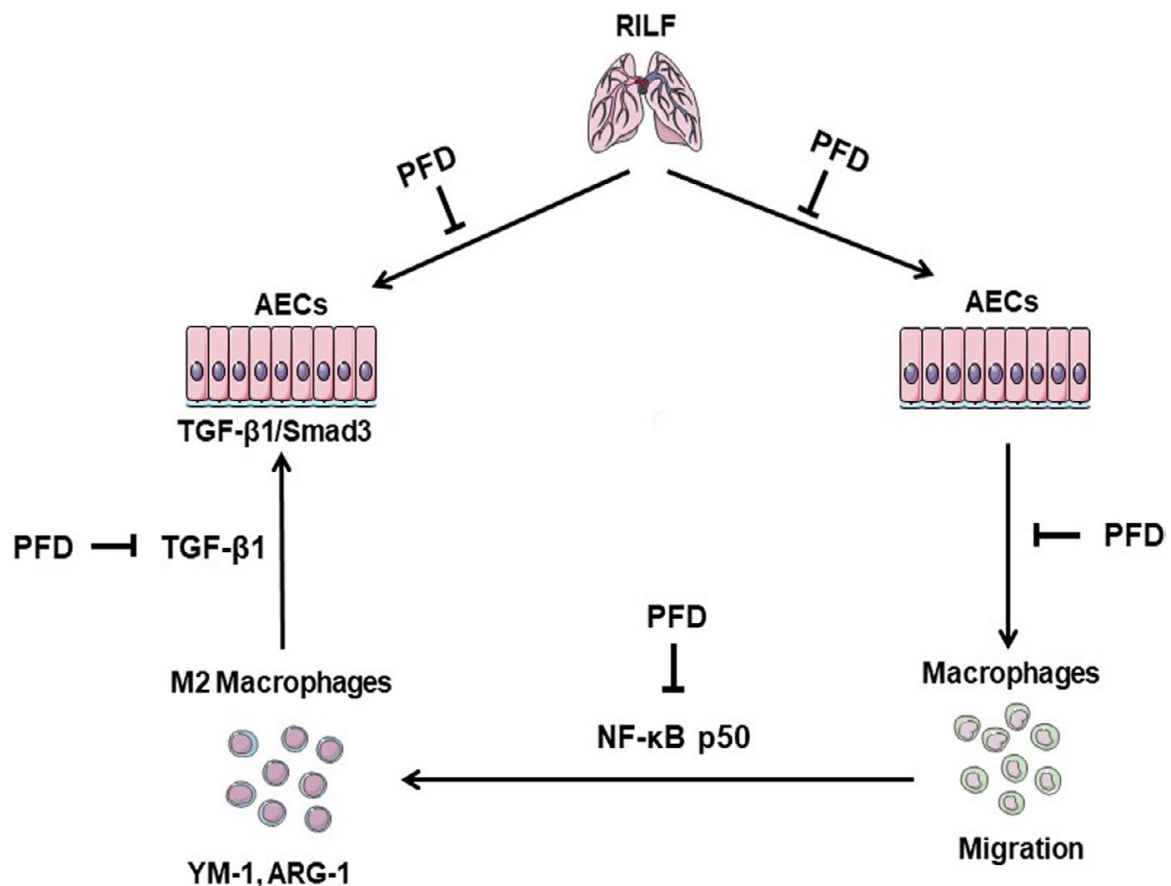

FIGURE 7 The working model of the preventive and therapeutic effects of PFD on RILF. PFD has a significant inhibitory effect on pulmonary fibrosis and fibrosis in other organs and is a broad-spectrum antifibrosis drug. In our study, we show that PFD protects against RILF by reducing the recruitment of M2 macrophages and inhibiting activation of the TGF- $\beta 1 /$ Smad3 signalling pathway. PFD is also involved in the crosstalk between macrophages and AECs: 1. PFD reduces the migration of macrophages by inhibiting the secretion of chemokines by MLE-12 cells induced by ionizing radiation. 2. PFD inhibits activation of the TGF- $\beta 1 /$ Smad3 signalling pathway in MLE-12 cells by inhibiting the secretion of TGF- $\beta 1$ by M2 macrophages. Here, we provide a new theoretical basis for the use of PFD in the treatment of RILF. Parts of the figure were drawn using images from Servier Medical Art (https://smart.servier.com/).

and that $100 \mu \mathrm{g} / \mathrm{ml}$ PFD for more than $48 \mathrm{~h}$ significantly inhibited the proliferation of PMVECs. Therefore, MLE-12 cells and PMVECs were stimulated with $100 \mu \mathrm{g} / \mathrm{ml}$ PFD for no more than $24 \mathrm{~h}$ for the following experiments (Figure 5B). After MLE-12 cells and PMVECs were subjected to $12 \mathrm{~Gy}$ irradiation, the expression of TGF- $\beta 1$ and $p$ Smad3 was upregulated. TGF- $\beta 1$ and $p$-Smad3 expression in MLE-12 cells and PMVECs was downregulated after pretreatment with PFD for $24 \mathrm{~h}$ in vitro (Figure 5C).

\section{5 | Pirfenidone is involved in the crosstalk between alveolar epithelial cells and macrophages}

The expression of granulocyte-macrophage colony-stimulating factor (GM-CSF), chemokine (C-C motif) ligand 2 (CCL2), chemokine (CX-C motif) ligand 1 protein (CXCL1), CXCL5, CXCL10 and CXCL16 in MLE-12 cells was evaluated at $24 \mathrm{~h}$ after irradiation with increasing doses of X-ray (Figure S3A). The secretion of CCL2 and CXCL1 in the culture supernatant of MLE-12 cells was also measured at $24 \mathrm{~h}$ after irradiation (Figure S3B), and the secretion of CCL2 and CXCL1 was inhibited by PFD treatment (Figure 6A). In addition, the Transwell assay showed that the migration of RAW264.7 cells induced by the conditioned medium of irradiated MLE-12 cells was also inhibited by PFD treatment in vitro (Figure 6C).
Transforming growth factor- $\beta 1$ expression in the culture supernatants of RAW264.7 cells was significantly elevated after induction with IL- 4 and IL-13. The expression of TGF- $\beta 1$ was also inhibited by PFD, and the expression was lower with increasing concentrations of PFD (Figure 6B). The protein expression of TGF- $\beta 1$ and $p$-Smad3 in MLE-12 cells was significantly elevated after culture with the supernatant of RAW264.7 cells stimulated with IL-4 and IL-13 for $24 \mathrm{~h}$, and these effects were inhibited by PFD treatment. The expression of TGF- $\beta 1$ and $p-S m a d 3$ in MLE-12 cells did not change in cell-free medium with or without IL-4 and IL-13 and PFD (Figure 6D). Taken together, these results demonstrated that PFD inhibited not only macrophage infiltration induced by chemokines secreted by irradiated MLE-12 cells but also macrophage production of TGF- $\beta 1$, which could affect the activation of TGF- $\beta 1 /$ Smad3 in MLE-12 cells.

\section{4 | DISCUSSION}

Radiotherapy plays a very important role in the treatment of thoracic tumours. It is critical to find effective drugs to treat RP and reduce the risk of RILF. Clinically, corticosteroids are mainly used to treat RP, and early intervention is expected to lead to recovery. Although the risk of RILF can be predicted by measuring many blood biochemical indexes, such as TGF- $\beta$, IL-6, Krebs von den Lungen- 6 (KL-6), surfactant 
proteins and interleukin-1 receptor antagonist (IL-1ra), ${ }^{22}$ most drugs for treating RILF are still in preclinical research. There are essentially no effective treatments for RILF. In the present study, we used a mouse model of RILF to investigate the antifibrotic effect of PFD. RILF is a slow progressive process that generally occurs 6-18 months after radiation in both animals and humans, ${ }^{23,24}$ and 15-20 Gy wholelung X-ray irradiation of mice is a common method to establish an RILF mouse model. ${ }^{25-27}$ However, in our study, the mice were irradiated with 50 Gy by a small animal radiation research platform (SARRP), which is different from other small animal irradiation systems in that it satisfies all of the following requirements: high dose rate, small beam diameter and accurate dose location based on image guidance. ${ }^{28}$ It has been reported that SARRP can improve the overall survival rate of mice by reducing lung side effects after high-precision heart irradiation. ${ }^{29}$ Fibrosis could be seen in the lungs of mice irradiated with $30 \mathrm{~Gy}$, while overt and intense fibrosis could be seen after irradiation with $60 \mathrm{~Gy}$ and $90 \mathrm{~Gy} .{ }^{30}$ Similarly, our results showed that pulmonary fibrosis in mice was severe at 150 days after $50 \mathrm{~Gy}$ irradiation, while orally administered $300 \mathrm{mg} / \mathrm{kg}$ PFD significantly attenuated pulmonary inflammatory infiltration and collagen accumulation. These antifibrotic effects are consistent with the results of different animal fibrosis studies. ${ }^{18,31}$

Using a prototypical model of RILF, we confirmed that the administration of PFD could significantly inhibit ionizing radiationinduced activation of the TGF- $\beta 1 / \mathrm{Smad} 3$ signalling pathway. In vitro, irradiation-induced activation of the TGF- $\beta 1 /$ Smad 3 signalling pathway was significantly inhibited by PFD at concentrations less than $100 \mu \mathrm{g} / \mathrm{ml}$ without cytotoxicity. This finding is consistent with a recent report that PFD has a wide range of antifibrotic effects, including the inhibition of TGF- $\beta 1 / \mathrm{Smad} 3$ signalling. ${ }^{32,33}$

A large number of animal experiments have shown that the occurrence of RILI is mainly caused by a series of pathophysiological reactions that interact with a variety of damaged cells and are regulated by a variety of cytokines. ${ }^{34}$ Macrophages play a key role in the development of RILI because they are the first line of defence against external invasion. ${ }^{35}$ The release of M2 cytokines has been reported to contribute to the excessive repair of damaged tissue and accelerate fibrosis, such as that induced by parasitic infections, ${ }^{36}$ fungal infections ${ }^{37}$ and bleomycin. ${ }^{38} \mathrm{M} 2$ cytokines play the same role in radiation-induced fibrosis in tissues or organs, such as the skin, ${ }^{39,40}$ intestine ${ }^{41}$ and lung. ${ }^{42}$ In our study, the recruitment of macrophages to the lungs of thoracically irradiated mice increased significantly, and most of them were M2 macrophages, which highly expressed ARG-1 and YM-1. PFD inhibited the polarization of M2 macrophages, which was characterized by a decrease in the $\mathrm{M} 2$ ratio and ARG-1 and YM-1 levels in vivo and in vitro. A previous study identified the p50 subunit of NF- $\mathrm{kB}$ as a key regulator of M2 macrophage polarization, ${ }^{43,44}$ and the downregulation of NF- $\mathrm{kB}$ p50 expression may be one of the mechanisms by which PFD inhibits the polarization of $\mathrm{M} 2$ macrophages.

We confirmed that macrophages cultured with IL-4 and IL-13 secreted high levels of TGF- $\beta 1$, while PFD could significantly inhibit the expression of TGF- $\beta 1$ by M 2 macrophages, which was consistent with the findings of Toda $\mathrm{M}$ et al. ${ }^{45}$ AECs can activate fibroblasts through epithelial-mesenchymal transition (EMT) and then differentiate into myofibroblasts, which form characteristic fibroblast foci and secrete extracellular matrix (ECM), leading to fibrosis. It has been reported that M2 macrophages but not M1 macrophages can induce EMT in AECs, and this process is mainly regulated by the TGF- $\beta 1 /$ Smad signalling pathway. ${ }^{46,47}$ Our current study showed that only conditioned medium from RAW264.7 cells treated with IL-4 and IL-13 increased the expression of TGF- $\beta 1$ and p-Smad3, and the same conditioned medium from RAW264.7 cells that had been treated with PFD $(100 \mu \mathrm{g} / \mathrm{ml})$ significantly suppressed TGF- $\beta 1$ and $\mathrm{p}$-Smad3. These findings suggested that PFD-induced inhibition of TGF- $\beta 1$ secretion by $\mathrm{M} 2$ macrophages prevents pulmonary fibrosis by inhibiting the TGF- $\beta 1 /$ Smad3 pathway in AECs.

Irradiated AECs can secrete a large amount of chemokines, such as CCL5, CCL2 and GM-CSF, ${ }^{47}$ which recruit inflammatory monocytes and neutrophils to the injured site. Our results showed that PFD could significantly inhibit the expression of multiple chemokines induced by ionizing radiation in MLE-12 cells. It has been reported that PFD reduces macrophage infiltration in nephrectomized rats $^{48}$ and inhibits both IL-17A-induced macrophage migration and MCP-1-induced macrophage migration in vitro. ${ }^{49}$ We hypothesize that PFD inhibits macrophage infiltration by reducing the secretion of chemokines from irradiated MLE-12 cells. Consistent with this hypothesis, we cultured macrophages with the supernatant from irradiated MLE-12 cells in Transwells. We found that the migration of macrophages was significantly enhanced in the presence of conditioned medium from irradiated MLE-12 cells, and PFD could impair macrophage migration to irradiated MLE-12 cell.

We have to admit that there is a deficiency in our study: although a number of animal studies have pointed out that $\mathrm{CMC}$ has no effect on histopathological and biochemical changes, ${ }^{50-52}$ compared with normal saline, the mice in NC group using $0.5 \% \mathrm{CMC}$ as control would be a better choice.

In conclusion, our findings indicated that PFD is a potential therapeutic agent to ameliorate fibrosis in RILF by reducing M2 macrophage infiltration and inhibiting the activation of TGF- $\beta 1 / \mathrm{Smad} 3$ signalling (Figure 7). A pilot study confirmed that PFD is effective in ameliorating the disability associated with RILF. ${ }^{53}$ Our cancer centre is also conducting a multicentre phase II clinical trial (NCT03902509) on the treatment of RILI with PFD. We believe that PFD will be beneficial RILF patients in the near future.

\section{ACKNOWLEDGEMENTS}

We give our sincere gratitude to the reviewers for their valuable suggestions.

\section{CONFLICT OF INTEREST}

None.

\section{AUTHOR CONTRIBUTIONS}

Hangjie Ying: Data curation (lead); Funding acquisition (equal); Writing-original draft (lead). Min Fang: Formal analysis (equal); Funding 
acquisition (equal); Methodology (equal). Qing Qing Hang: Data curation (equal); Methodology (equal). Yamei Chen: Data curation (equal); Methodology (equal). Xu Qian: Investigation (supporting); Project administration (supporting). Ming Chen: Project administration (lead).

\section{ORCID}

Hangjie Ying (D) https://orcid.org/0000-0001-8779-7144

\section{REFERENCES}

1. Baker S, Dahele M, Lagerwaard FJ, Senan S. A critical review of recent developments in radiotherapy for non-small cell lung cancer. Radiat Oncol. 2016;11:115.

2. Zhang M, Wu AJ. Radiation techniques for esophageal cancer. Chin Clin Oncol. 2017;6:45.

3. Urwin R, Barrington SF, Mikhaeel NG. Role of PET imaging in adaptive radiotherapy for lymphoma. Q J Nucl Med Mol Imaging. 2018;62:411-419.

4. Castaneda SA, Strasser J. Updates in the treatment of breast cancer with radiotherapy. Surg Oncol Clin N Am. 2017;26:371-382.

5. Yavas G, Calik M, Calik G, Yavas C, Ata O, Esme H. The effect of halofuginone in the amelioration of radiation induced-lung fibrosis. Med Hypotheses. 2013;80:357-359.

6. Rajan Radha R, Chandrasekharan G. Pulmonary injury associated with radiation therapy - assessment, complications and therapeutic targets. Biomed Pharmacother. 2017;89:1092-1104.

7. Ying $\mathrm{H}$, Kang $\mathrm{Y}$, Zhang $\mathrm{H}$, et al. MiR-127 modulates macrophage polarization and promotes lung inflammation and injury by activating the JNK pathway. J Immunol. 2015;194:1239-1251.

8. Zhang H, Han G, Liu H, et al. The development of classically and alternatively activated macrophages has different effects on the varied stages of radiation-induced pulmonary injury in mice. J Radiat Res. 2011;52:717-726.

9. Iyer SN, Wild JS, Schiedt MJ, Hyde DM, Margolin SB, Giri SN Dietary intake of pirfenidone ameliorates bleomycin-induced lung fibrosis in hamsters. J Lab Clin Med. 1995;125:779-785.

10. Sun YW, Zhang YY, Ke XJ, Wu XJ, Chen ZF, Chi P. Pirfenidone prevents radiation-induced intestinal fibrosis in rats by inhibiting fibroblast proliferation and differentiation and suppressing the TGF- $\beta 1 /$ Smad/CTGF signaling pathway. Eur J Pharmacol. 2018;822:199-206.

11. Cui $Y$, Zhang $M$, Leng $C$, et al. Pirfenidone inhibits cell proliferation and collagen I production of primary human intestinal fibroblasts. Cells. 2020;9(3):775.

12. Jin J, Togo S, Kadoya K, et al. Pirfenidone attenuates lung fibrotic fibroblast responses to transforming growth factor- $\beta 1$. Respir Res. 2019;20(1):119.

13. Pourgholamhossein F, Rasooli R, Pournamdari M, et al. Pirfenidone protects against paraquat-induced lung injury and fibrosis in mice by modulation of inflammation, oxidative stress, and gene expression. Food Chem Toxicol. 2018;112:39-46.

14. Rasooli R, Pourgholamhosein F, Kamali Y, Nabipour F, Mandegary A. Combination therapy with pirfenidone plus prednisolone ameliorates paraquat-induced pulmonary fibrosis. Inflammation. 2018;41:134-142.

15. Noble PW, Albera C, Bradford WZ, et al. Pirfenidone in patients with idiopathic pulmonary fibrosis (CAPACITY): two randomised trials. Lancet. 2011;377:1760-1769.

16. King TE Jr, Bradford WZ, Castro-Bernardini S, et al. A phase 3 trial of pirfenidone in patients with idiopathic pulmonary fibrosis. $N$ Engl J Med. 2014:370:2083-2092.

17. Qin W, Liu B, Yi M, et al. Antifibrotic agent pirfenidone protects against development of radiation-induced pulmonary fibrosis in a murine model. Radiat Res. 2018;190:396-403.
18. Li G, Ren J, Hu Q, et al. Oral pirfenidone protects against fibrosis by inhibiting fibroblast proliferation and TGF- $\beta$ signaling in a murine colitis model. Biochem Pharmacol. 2016;117:57-67.

19. Sandoval-Rodriguez A, Monroy-Ramirez HC, Meza-Rios A, et al. Pirfenidone is an agonistic ligand for PPAR $\alpha$ and improves NASH by activation of SIRT1/LKB1/pAMPK. Hepatol Commun. 2020;4:434-449.

20. Ashcroft T, Simpson JM, Timbrell V. Simple method of estimating severity of pulmonary fibrosis on a numerical scale. J Clin Pathol. 1988;41:467-470.

21. Mota A, Jiménez-Garcia L, Herránz S, de Las HB, Hortelano S. $\alpha$-Hispanolol sensitizes hepatocellular carcinoma cells to TRAILinduced apoptosis via death receptor up-regulation. Toxicol Appl Pharmacol. 2015;286(3):168-177.

22. Kong FM, Ao X, Wang L, Lawrence TS. The use of blood biomarkers to predict radiation lung toxicity: a potential strategy to individualize thoracic radiation therapy. Cancer Control. 2008;15:140-150.

23. Travis EL, Tucker SL. The relationship between functional assays of radiation response in the lung and target cell depletion. $\mathrm{Br} J$ Cancer Suppl. 1986;7:304-319.

24. Siemann DW, Hill RP, Penney DP. Early and late pulmonary toxicity in mice evaluated 180 and 420 days following localized lung irradiation. Radiat Res. 1982;89:396-407.

25. Li X, Xu G, Qiao T, et al. Effects of CpG Oligodeoxynucleotide 1826 on transforming growth factor-beta 1 and radiation-induced pulmonary fibrosis in mice. J Inflamm. 2016;1(3):16.

26. Zhang C, Zhao H, Li BL, Fu-Gao LH, Cai JM, Zheng M. CpGoligodeoxynucleotides may be effective for preventing ionizing radiation induced pulmonary fibrosis. Toxicol Lett. 2018;292:181-189.

27. Bickelhaupt S, Erbel C, Timke C, et al. Effects of CTGF blockade on attenuation and reversal of radiation-induced pulmonary fibrosis. $J$ Natl Cancer Inst. 2017;109(8). https://doi.org/10.1093/jnci/djw339

28. Cho J, Kodym R, Seliounine S, Richardson JA, Solberg TD, Story MD. High dose-per-fraction irradiation of limited lung volumes using an image-guided, highly focused irradiator: simulating stereotactic body radiotherapy regimens in a small-animal model. Int J Radiat Oncol Biol Phys. 2010;77(3):895-902.

29. Sievert W, Stangl S, Steiger K, Multhoff G. Improved overall survival of mice by reducing lung side effects after high-precision heart irradiation using a small animal radiation research platform. Int J Radiat Oncol Biol Phys. 2018;101(3):671-679.

30. Hong ZY, Lee CG, Shim HS, et al. Time, dose, and volume responses in a mouse pulmonary injury model following ablative irradiation. Lung. 2016;194:81-90.

31. Li Y, Li H, Liu S, et al. Pirfenidone ameliorates lipopolysaccharideinduced pulmonary inflammation and fibrosis by blocking NLRP3 inflammasome activation. Mol Immunol. 2018;99:134-144.

32. Ma Z, Zhao C, Chen Q, et al. Antifibrotic effects of a novel pirfenidone derivative in vitro and in vivo. Pulm Pharmacol Ther. 2018;53:100-106.

33. Conte E, Gili E, Fagone E, Fruciano M, lemmolo M, Vancheri C. Effect of pirfenidone on proliferation, TGF- $\beta$-induced myofibroblast differentiation and fibrogenic activity of primary human lung fibroblasts. Eur J Pharm Sci. 2014;58:13-19.

34. Lu L, Sun C, Su Q, et al. Radiation-induced lung injury: latest molecular developments, therapeutic approaches, and clinical guidance. Clin Exp Med. 2019;19:417-426.

35. Murthy S, Larson-Casey JL, Ryan AJ, He C, Kobzik L, Carter AB. Alternative activation of macrophages and pulmonary fibrosis are modulated by scavenger receptor, macrophage receptor with collagenous structure. FASEB J. 2015;29:3527-3536.

36. Chiaramonte MG, Mentink-Kane M, Jacobson BA, et al. Regulation and function of the interleukin 13 receptor alpha 2 during a $\mathrm{T}$ helper cell type 2-dominant immune response. J Exp Med. 2003;197:687-701. 
37. Blease K, Jakubzick C, Schuh JM, Joshi BH, Puri RK, Hogaboam CM IL-13 fusion cytotoxin ameliorates chronic fungal-induced allergic airway disease in mice. J Immunol. 2001;167:6583-6592.

38. Jakubzick C, Choi ES, Joshi BH, et al. Therapeutic attenuation of pulmonary fibrosis via targeting of IL-4- and IL-13-responsive cells. J Immunol. 2003;171:2684-2693.

39. Horton JA, Hudak KE, Chung EJ, et al. Mesenchymal stem cells inhibit cutaneous radiation-induced fibrosis by suppressing chronic inflammation. Stem Cells. 2013;31:2231-2241.

40. Riccobono D, Nikovics K, François S, et al. First insights into the M2 inflammatory response after adipose-tissue-derived stem cell injections in radiation-injured muscles. Health Phys. 2018;115:37-48.

41. Rannou E, François A, Toullec A, et al. In vivo evidence for an endothelium-dependent mechanism in radiation-induced normal tissue injury. Sci Rep. 2015;5:15738.

42. Duru N, Wolfson B, Zhou Q. Mechanisms of the alternative activation of macrophages and non-coding RNAs in the development of radiation-induced lung fibrosis. World J Biol Chem. 2016;7:231-239.

43. Porta C, Rimoldi M, Raes G, et al. Tolerance and M2 (alternative) macrophage polarization are related processes orchestrated by p50 nuclear factor kappaB. Proc Natl Acad Sci USA. 2009;106:14978-14983.

44. Lu H, Wu L, Liu L, et al. Quercetin ameliorates kidney injury and fibrosis by modulating M1/M2 macrophage polarization. Biochem Pharmacol. 2018;154:203-212.

45. Toda M, Mizuguchi S, Minamiyama Y, et al. Pirfenidone suppresses polarization to $\mathrm{M} 2$ phenotype macrophages and the fibrogenic activity of rat lung fibroblasts. J Clin Biochem Nutr. 2018;63:58-65.

46. Zhu L, Fu X, Chen X, Han X, Dong P. M2 macrophages induce EMT through the TGF- $\beta /$ Smad2 signaling pathway. Cell Biol Int. 2017;41:960-968.

47. Park HR, Jo SK, Jung U. Ionizing radiation promotes epithelial-tomesenchymal transition in lung epithelial cells by TGF- $\beta$-producing M2 macrophages. In Vivo. 2019;33:1773-1784.
48. Chen JF, Ni HF, Pan MM, et al. Pirfenidone inhibits macrophage infiltration in 5/6 nephrectomized rats. Am J Physiol Renal Physiol. 2013;304:F676-F685

49. Du J, Paz K, Flynn R, et al. Pirfenidone ameliorates murine chronic GVHD through inhibition of macrophage infiltration and TGF- $\beta$ production. Blood. 2017;129:2570-2580.

50. Mondal MI, Yeasmin MS. Toxicity study of food-grade carboxymethyl cellulose synthesized from maize husk in Swiss albino mice. Int J Biol Macromol. 2016;92:965-971.

51. Rowe VK, Spencer HC, Adams EM, Irish DD. Response of laboratory animals to cellulose glycolic acid and its sodium and aluminum salts. J Food Sci. 1944;9:175-182.

52. Shelanski HA, Clark AM. Physiological action op sodium carboxymethyl-cellulose on laboratory animals and humans. J Food Sci. 1948;13:29-35.

53. Simone NL, Soule BP, Gerber L, et al. Oral pirfenidone in patients with chronic fibrosis resulting from radiotherapy: a pilot study. Radiat Oncol. 2007;2:19.

\section{SUPPORTING INFORMATION}

Additional supporting information may be found online in the Supporting Information section.

How to cite this article: Ying $\mathrm{H}$, Fang $\mathrm{M}$, Hang QQ, Chen $\mathrm{Y}$, Qian X, Chen M. Pirfenidone modulates macrophage polarization and ameliorates radiation-induced lung fibrosis by inhibiting the TGF- $\beta 1 / \mathrm{Smad} 3$ pathway. J Cell Mol Med. 2021;25:8662-8675. https://doi.org/10.1111/jcmm.16821 